\title{
The Profile of Students' Scientific Literacy Competence Skill at SMA Batik 2 Surakarta
}

\author{
Shofwan Ridho ${ }^{1, a)}$, Nonoh Siti Aminah ${ }^{1, b)}$, Agus Supriyanto ${ }^{2, c)}$ \\ ${ }^{1}$ Physics Education Department of Postgraduate Program, Universitas Sebelas Maret, Surakarta, \\ Indonesia \\ ${ }^{2}$ Physics Department of Postgraduate Program, Universitas Sebelas Maret, Surakarta, Indonesia \\ $\bowtie:{ }^{\text {a) }}$ Shofwan.r@gmail.com, ${ }^{\text {b) }}$ nonoh_nst@yahoo.com, ${ }^{\text {c) }}$ agusf22@staff.uns.ac.id
}

\begin{abstract}
Some research showed that many teachers have literacy skills, but they have not used them in the classroom yet. This research aims to describe scientific literacy competence of SMA Batik 2 Surakarta students and teacher. The research used a qualitative descriptive method. The study was conducted at SMA Batik 2 Surakarta with 10th grade science class students as the subjects. There were 88 students as and two teachers the subjects. The samples selected by using total sampling technique. The research instrument used in this study is scientific literacy test adapted from PISA (Programme for International Student Assesment). The data analysis technique used is percentage. The result of this study shows that $57.41 \%$ student mastered the scientific literacy competence, the student completed in scientific literacy competence included in the middle level of this research. The interviews with teachers and students show that the use of scientific literacy in the classroom is still low. This research is complementary to the study of the importance of teacher ability analysis in the use of scientific literacy skill in the classroom. Scientific literacy skills that are applied in learning will make students have adequate scientific literacy skills, equivalent to other countries.
\end{abstract}

Keywords: scientific literacy skill, qualitative descriptive

\section{INTRODUCTION}

At the high school level, physics is considered important to be studied with some considerations: (1) Physics is intended as a place to cultivate the ability to think useful for solving problems in everyday life; (2) Physics needs to be studied for a more specific purpose of equipping learners with knowledge, understanding, and the number of abilities required to enter higher education and to develop science and technology; (3) Physics is conducted in scientific inquiry to cultivate the ability to think, work, and be scientific and communicate as one of the important aspects of Life Skills (Departemen Pendidikan Nasional 2006). The importance of physics as part of science is for technological development also useful in the development of students' scientific abilities, improving problem-solving skills, providing better job opportunities as well as development community culture. As science progresses, more developments and innovations will happen, which may bring up issues and debates around them. A society with a higher scientific literacy would be able to make better decisions.

The term scientific literacy was introduced in 1950. Scientific literacy has several definitions of a thorough discussion and a long history. Hurd first introduced the term scientific literacy and defines the scientific literacy as making a decision which includes responsibility for science and technology 
and having the intellectual knowledge and skills for cognitive movement (Hurd 1985). Deboer (2000) states that scientific literacy is to provide a broad understanding of science and the rapidly developing scientific enterprise or not. That is, scientific literacy is for all students, regardless of whether the student will become a scientist or not. Scientific literacy is the knowledge and understanding of scientific concepts and processes required for personal decision making, participation in civic and cultural affairs, and economic productivity. It also includes specific types of abilities (National Research Council 1996). Based on this understanding, the emphasis of scientific literacy is not only knowledge and understanding of science concepts and processes but also directed to how one can make decisions and participate in social life, culture, and economic growth. According to Trefil (2008) that scientific literacy can be categorized into four categories between (1) Cultural scientific literacy that is understanding science by a person with average intelligence and cultural education; (2) Civic Scientific Literacy is the scientific understanding needed to make a decision; (3) The Scientific Literacy Practice is the scientific knowledge one needs to solve the practice of the problem; (4) Aesthetic Literacy and Consumer Science is a scientific and phenomenal knowledge law enhancing our appreciation of life itself through the beauty. From several scientific literacy definitions, the OECD (1998) with the PISA study looked at the scientific literacy as the capacity to use scientific knowledge, to identify questions and to draw the decisions about the natural world and the changes made to it through human activity.

The development of this definition was modified by PISA into three dimensions (OECD 2007). First, the scientific concepts necessary to understand certain phenomena of nature and the changes made through human activity. Second, the scientific process, which centers on the ability to obtain, interpret and act on evidence. The five processes in the OECD / PISA relate to: (1) the recognition of scientific questions; (2) the identification of evidence; (3) conclusion; (4) communication of this conclusion; (5) demonstration of understanding of scientific concepts. Third, the scientific situation, especially chosen from everyday life rather than from the practice of science in school, or the work of professional scientists. Developing scientific literacy is important because: (1) understanding of science offers personal satisfaction and pleasure that comes after understanding and studying nature; (2) everyone needs information and science thinking for decision making in their daily life; (3) everyone needs to use their abilities in public discourse and debate about important issues involving science and technology; (4) scientific literacy is important in the world of work, as more and more jobs requiring high skills, thus requiring people to learn science, to reason, to think creatively, make decisions, and solve problems (National Research Council 1996).

The Programme for International Student Assessment (PISA) is an ongoing triennial survey that assesses the extent to which 15-year-olds students near the end of compulsory education have acquired key knowledge and skills that are essential for full participation in modern societies. PISA is operated by the Organization for Economic Cooperation and Development (OECD) (OECD 2016). Indonesia is one of 72 countries that have participated in scientific literacy studies from PISA since 2000. The average score of Indonesian scientific literacy based on the results of the successive PISA study in 2009, 2012 and 2015 is 383, 382, and 403. From 72 countries, Indonesia ranks 64th in 2012 and in 2015 Indonesia is ranked 62th on scientific literacy (Kementerian dan Kebudayaan 2006).

In addition to the results of the PISA survey, scientific literacy has been surveyed by TIMMS (Trends in International Mathematics and Science Study) conducted every four years. Indonesia's ranking in 2011 is 40 out of 42 countries. In the year 2015 with the category of 4 th grade elementary school obtained rank 45 of 48 countries (Mullis 2016). Based on the results of scientific literacy studies conducted by PISA and TIMSS, the ability of Indonesian students in competing at the international level should still be improved.

Scientific assessment PISA prioritizes competence on the identifying scientific issues, explain phenomenon scientifically, and using scientific evidence. The competency identifying scientific issues includes: (1) Recognizing questions that it would be possible to investigate scientifically in a given situation; (2) Identifying keywords to search for scientific information on a given topic; (3) Recognizing key features of a scientific investigation. The competency explains phenomenon scientifically includes: (1) Applying knowledge of science in a given situation; (2) Describing or interpreting phenomena scientifically and predicting changes; (3) Identifying appropriate descriptions, explanations, and predictions. The competency using scientific evidence includes: 
(1) Interpreting scientific evidence and making and communicating conclusions; (2) Identifying the assumptions, evidence, and reasoning behind conclusions; (3) Reflecting on the societal implications of science and technological developments.

The objective of PISA based on OECD (2013) is to describe the extent to which students can apply their knowledge in contexts of relevance to their lives. Accordingly, the assessed knowledge will be selected from the major fields of physics, chemistry, biology, Earth and space science, and technology according to (1) The relevance to real-life situations, scientific knowledge differs in the degree to which it is useful in the life of individuals; (2) The knowledge selected represents important scientific concepts and thus has enduring utility; (3) The knowledge selected is appropriate to the developmental level of 15-year-old students.

Departemen Pendidikan Nasional (2007) has made science curriculum policies relevant to the facts about PISA results on the average literacy conditions of Indonesian students. This study was conducted by (Pusat Kurikulum Badan Penelitian dan Pengembangan Departemen Pendidikan Nasional). Recommended in the academic script, including: (1) Science learning can build students' self-esteem, which makes students confident that they are capable of learning science and they consider that science lessons are not a lesson to be feared; (2) Learning science should be accompanied by building the attitude and scientific skills, so that science learning not only learns the concepts; (3) Science learning should enable students to develop their reasoning ability and can plan and conduct scientific inquiry, and can use their knowledge to understand the natural events that occur in the vicinity; (4) Science learning should be able to revitalize the "science process skills" for students, teachers and prospective teachers as the main mission of IPA in schools to develop the ability to observe, plan inquiry, interpret data and information (narration, drawings, charts, tables) and draw conclusions.

From the observation of the learning process in grade X SMA Batik 2 Surakarta seen that the role of teachers in the learning process less support the development of literacy skills of science students. This is because in the learning process the teacher does not identify the scientific issues that can build thinking skills such as introductory text, drawings, scenarios of problems that occur in the vicinity or materials and props newly known by students. Submission of materials is mostly done by lecture methods and less involving students to be active in the class, thus less building aspects of student scientific literacy. Based on the above description then the scientific literacy is important to note, the authors are interested to research to obtain a description of scientific literacy students class X SMA Batik 2 Surakarta.

\section{RESEARCH METHODOLOGY}

This research use survey method which conducted in SMA Batik 2 Surakarta in January 2018. The purpose of this research is to know the students' and teacher scientific literacy skill profile. Subjects in this study were 88 students consisting of 30 students of class X MIPA 1, 24 students of class X MIPA 2 and 34 students of class X MIPA 3.

The instruments used in this survey are 20 multiple choice questions adopted from PISA tests consistent with Physics subjects. The test consists of five questions on the scientific literacy competence; there are five questions on the identifying scientific issues, eight questions on the explaining the competence of scientifically phenomena and seven questions on the competence of using scientific evidence (OECD 2009). Themes on the scientific literacy test are shown in TABLE 1. 
TABLE 1. The themes on the scientific literacy test

\begin{tabular}{|c|c|c|c|}
\hline No & Scientific Competencies & Theme & Item \\
\hline 1 & identifying scientific issues & $\begin{array}{l}\text { Buses, The Grand } \\
\text { Canyon, Sunscreens, } \\
\text { Transit of Venus, } \\
\text { Starlight }\end{array}$ & $1,4,6,16,14$ \\
\hline 2 & $\begin{array}{l}\text { explaining phenomena } \\
\text { scientifically }\end{array}$ & $\begin{array}{l}\text { Daylight, Clothes, The } \\
\text { Grand Canyon, Hot } \\
\text { Work, Tobacco } \\
\text { Smoking, Starlight, } \\
\text { Transit of Venus, Wind } \\
\text { Farms }\end{array}$ & $2,3,5,8,12,15,17,20$ \\
\hline 3 & using scientific evidence & $\begin{array}{l}\text { Acid Rain, Tooth } \\
\text { Decay, Tooth Decay, } \\
\text { Lenses, Ozone, Wind } \\
\text { Farms }\end{array}$ & $7,9,10,11,13,18,19$ \\
\hline
\end{tabular}

The students' scientific literacy skill levels were grouped into three categories according to TABLE 2.

TABLE 2. Category of scientific literacy skill

\begin{tabular}{ccc}
\hline No. & Interval & Category \\
\hline 1 & $81-100$ & Very High \\
2 & $61-80$ & High \\
3 & $41-60$ & Medium \\
4 & $21-40$ & Low \\
5 & $0-20$ & Very Low \\
\hline
\end{tabular}

\section{RESULTS AND DISCUSSION}

You can delete this section as he From the survey, the scientific literacy skill score was obtained. The following TABLE 3 illustrates the scientific literacy skill of all students of X-MIPA SMA Batik 2 Surakarta.

TABLE 3. Statistic of Scientific literacy Test Result

\begin{tabular}{lc}
\hline \multicolumn{1}{c}{ Statistics } & Value Statistics \\
\hline Number of subjects & 88 \\
Minimum ideal score & 0,00 \\
Ideal score maximum & 100,00 \\
Minimum score & 34,29 \\
Maximum score & 87,50 \\
Average score & 57,41 \\
Standard deviation & 11,62 \\
Variance & 135,08 \\
\hline
\end{tabular}

TABLE 3 shows that from the maximum ideal score is entered gained an average score is 57.41 with a standard deviation 135.08. From the Table 3 also obtained the variance of 135.08. Based on the normality test obtained significance of 0.429 with a significance level of 0.05 so it can be said that the data is normally distributed. 
TABLE 4. Tests of Normality

\begin{tabular}{lccccccc}
\hline & \multicolumn{3}{c}{ Kolmogorov-Smirnov $^{\mathrm{a}}$} & \multicolumn{3}{c}{ Shapiro-Wilk } \\
\hline & Statistic & Df & \multicolumn{1}{c}{ Sig. } & Statistic & df & Sig. \\
\hline Scientific Literacy Skill & .084 & & 88 & .176 & .985 & 88 & .429 \\
\hline
\end{tabular}

a. Lilliefors Significance Correction

In this study, the students answer were analyzed according to the scoring rubric having been made in the previous stage. The analysis of the student's answer is done by using a descriptive approach, by giving a score of each stage of the correct answer given by each student. The measurement results were then analyzed descriptively to determine the level of student's achievement on scientific literacy skill. In addition, student's achievement percentage of each indicator on scientific literacy skill is presented in TABLE 5 .

TABLE 5. Percentages of Scientific Literacy Skills

\begin{tabular}{clcc}
\hline No & \multicolumn{1}{c}{ Theme } & Score & Percentage (\%) \\
\hline 1 & Buses (S127Q01) & 57 & 65 \\
2 & Daylight (S129Q01) & 58 & 66 \\
3 & Clothes (S213Q02) & 10 & 11 \\
4 & The Grand Canyon (S426Q05) & 62 & 70 \\
5 & The Grand Canyon (S426Q03) & 71 & 81 \\
6 & Sunscreens (S447Q02) & 69 & 78 \\
7 & Acid Rain (S506Q01) & 32 & 36 \\
8 & Hot Work (S420Q03) & 67 & 76 \\
9 & Tooth Decay (S414Q01) & 28 & 32 \\
10 & Tooth Decay(S414Q04) & 38 & 43 \\
11 & Adjustable Glasses (CS621Q01) & 40 & 45 \\
12 & Tobacco Smoking (S439Q01) & 32 & 36 \\
13 & Ozone (S253Q02) & 50 & 57 \\
14 & Starlight (S441Q01) & 74 & 84 \\
15 & Starlight (S441Q02) & 59 & 67 \\
16 & Transit of Venus (S507Q01) & 79 & 90 \\
17 & Transit of Venus (S507Q02) & 32 & 36 \\
18 & Wind Farms (S529Q01) & 56 & 64 \\
19 & Wind Farms (S529Q02) & 15 & 17 \\
20 & Wind Farms (S529Q03) & 42 & 48 \\
\hline
\end{tabular}

TABLE 5 shows the percentage of student's achievement in the indicator of scientific literacy skill. The analysis results show that the highest and lowest percentages of scientific literacy skill are Transit of Venus (S507Q01) theme (90\%) and Clothes (S213Q02) theme (11\%) respectively.

TABLE 6. Frequency Distribution and Cumulative percentage from Students Answer Literacy Skill

\begin{tabular}{lllcccc}
\hline No & \multicolumn{1}{c}{ Scientific Competencies } & \multicolumn{1}{c}{ Items } & $\mathrm{N}$ & Min & Max & Average \\
\hline 1 & Identifying scientific issues (ISI) & $1,4,6,14,16$ & 88 & 20.00 & 100.00 & 77.50 \\
2 & Explaining phenomena scientifically & $2,3,5,8,12$, & 88 & 0.00 & 88.00 & 52.70 \\
& (EPS) & $15,17,20$ & & & & \\
3 & Using scientific evidence (USE) & $7,9,10,11,13$, & 88 & 0.00 & 100.00 & 42.05 \\
\hline
\end{tabular}

Table 6 shows the scientific literacy skill of students in each competency. The condition to indicate that the student has not fully optimized science process in scientific literacy skill. The low students' learning outcomes associated with the low scientific literacy skills. TABLE 6 can be presented in the form of a bar chart in FIGURE 1. 


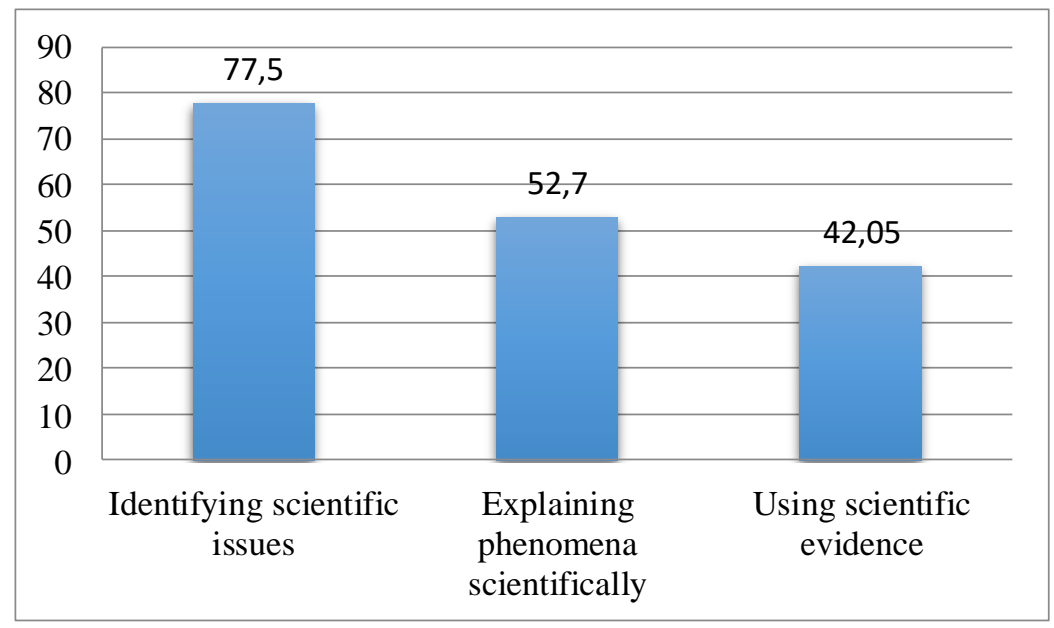

FIGURE 1. Graph percentage of Student's Answer Based on Ability Level of Scientific literacy

FIGURE 1 shows that student's answers in class X MIPA in the identifying scientific issues competencies as many as $77.50 \%$, explaining phenomena scientifically competencies as many as $52.70 \%$ and Using scientific evidence competencies as many as $42.05 \%$. It can be seen that the average score of the using scientific evidence was lower in scientific competencies. The low result of the explaining scientiifc issues competencies were also shown in the other study on the cycle theme (Rusilowati et al. 2016). This result indicates that students were generally only able to know the concept, principles, theories, or science formulas but their comprehension limited on the definition aspects.

The reason, they consider the text or the description of any question is too long, so they cannot catch the essence of the description of the question. One of the factors that affect scientific literacy achievement is the ability to read. The reason expressed by the students indicate that reading ability of student is a medium. The possible implications of a lack of interest in reading are low. Low interest in reading allows the student to be lazy to read and become less conscientious because in a hurry to read.

This also supports the result of student interviews. Low interest in reading, especially reading about the whole concept on the description or the form of scientific process questions seems not familiarized by the science teacher. This is supporting by assessment created by teachers; wich is almost $90 \%$ of the questions that are made, accumulated on memorizing (C1), while the demands on scientific literacy is a content which form problem solving (C3) and analysis (C4). One of scientific literacy core is the ability to identify problems. Therefore to improve the achievements of student's scientific literacy should be faced with the problem of daily life. According to the interview result, $65 \%$ of student claim that the teacher in class still rarely gave the problem analysis of any graphs or table. However, the ability to interpret results in table forms and graphic form is part of the indicator to be a human or scientifically literate student. Memorizing content is more disliked by students. Most of the students prefer the identification of problem as in scientific problem. Based on the interview, one of the other reason for the student's low scientific literacy as there are some science terms or concepts that have not been understood by the student. If analyzed existing concept in scientific literacy test, all concepts that are expected to be studied by the students of class X. This indicates the possibility of student comprehension of the content presented by the teacher might be still low. 


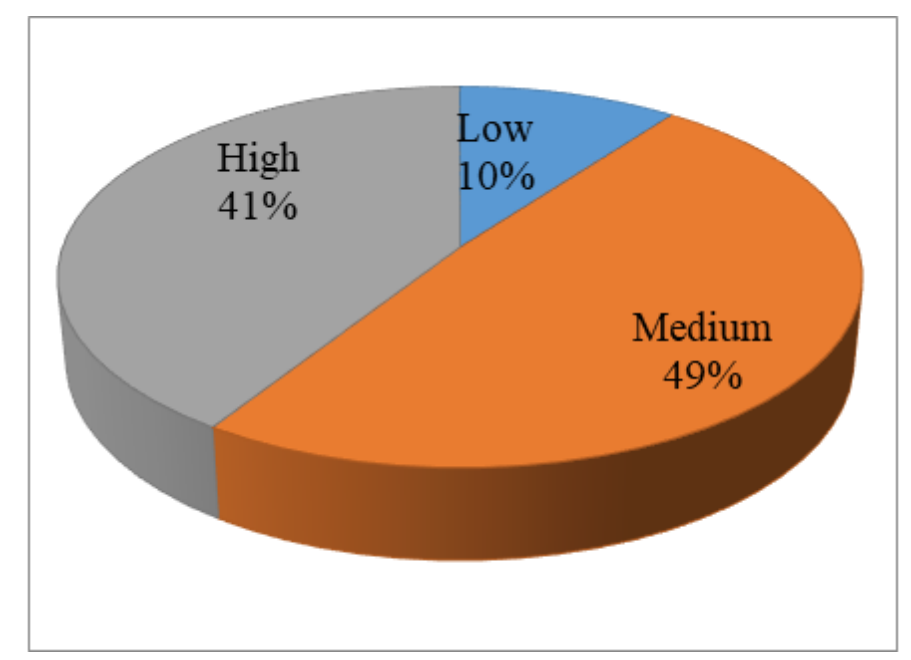

FIGURE 2. Distribution of Student Achievement in Scientific Literacy

The theme of gender equity is widely promoted, so it is making OECD always discussed the result of scientific literacy by comparing the score of boy and girl students. Therefore, this study will discuss a comparison among gender as a form of student profile scientific literacy. The result that boy and girls achieved showed in TABLE 7.

TABLE 7. Scientific literacy Result Comparing Among Gender

\begin{tabular}{lcccc}
\hline \multirow{3}{*}{ Gender } & \multicolumn{3}{c}{ Scientific Competencies } & \multirow{2}{*}{ Average } \\
\cline { 2 - 4 } & $\begin{array}{c}\text { Identifying scientific } \\
\text { issues (ISI) }\end{array}$ & $\begin{array}{c}\text { Explaining phenomena } \\
\text { scientifically (EPS) }\end{array}$ & $\begin{array}{c}\text { Using scientific evidence } \\
\text { (USE) }\end{array}$ & 60.53 \\
\hline Boys & 73.85 & 58.65 & 49.08 & 61.85 \\
Girls & 76.73 & 58.67 & 50.15 & 6 \\
\hline
\end{tabular}

Based on TABLE 7, the score of scientific literacy girls is higher than boys. This result shows some improvements in the skills of students. In particular, girls are performing better than boys in all subjects: science, literacy, mathematics. They are significantly better at reading. These result also shows girls are significantly more likely than boys to want a science-related career. Statistical comparison (ANOVA) using SPSS, showed that the achievement of student scientific literacy of boys and girl in SMA Batik 2 Surakarta is not different significantly.

Based on the results of the research, the researcher argued about the need for efforts to improve scientific literacy skills. One way that physics teachers can do is the application of scientific literacy in learning is needed to prepare students who are literate (Sultan et al. 2018). The implication of this scientific literacy results in the next research will be applied in making learning plans.

\section{CONCLUSIONS}

Students at SMA Batik 2 Surakarta achieved scientific literacy categorized into medium category. Scientific literacy competency that categorized into high category is only identifying scientific issues. Explaining phenomena scientifically and using scientific evidence categorized into medium category. Girls have higher scientific literacy than the boys, but the differences are not statistically significant. Scientific literacy skills that are applied in learning will make students have adequate scientific literacy skills, equivalent to other countries.

\section{REFERENCES}

Deboer, GE 2000, 'Scientific Literacy: Another Look at Its Historical and Contemporary Meaning and Its Relationship to Science Education Reform,' Journal of Research in Science, vol. 37, pp. 582-601. 
Departemen Pendidikan Nasional 2006, Permendiknas No 22 Tahun 2006, Jakarta.

Departemen Pendidikan Nasional 2007, Kajian Kurikulum Mata Pelajaran IPA, Jakarta.

Hurd, P 1985, 'Science Education For A New Age: The Reform Movement', NASSP Bulletin, vol. 9, pp. 83-92

Kementerian dan Kebudayaan 2006, Peringkat dan Capaian Indonesia Mengalami Peningkatan, vol. 4, pp. 15.

Mullis, IVS, Martin, MO, \& Foy, P 2016, TIMSS Advanced 2015 International Results in Advanced Mathematics and Physics, Chestnut Hill, MA, TIMSS \& PIRLS International Study Center, Boston College.

National Research Council (NRC) 1996, National Science Education Standards, National Academy Press, Washington.

Organisation for Economic Cooperation and Development (OECD) 1998, Instrument design: A framework for assessing scientific literacy. Report of Project Managers Meeting, OECD Publishing, Netherlands.

Organisation for Economic Cooperation and Development (OECD) 2007, Assessing scientific, reading and mathematical literacy: A framework for PISA 2006, OECD Publishing, Paris.

Organisation for Economic Cooperation and Development (OECD) 2009, Take the Test Sample Questions from OECD's PISA Assessments, OECD Publishing, Paris.

Organisation for Economic Cooperation and Development (OECD) 2013, PISA 2012 Assessement and Analytical Framework: Mathematics, Reading, Science, Problem Solving and Financial Literacy, OECD Publishing, Paris.

Organisation for Economic Cooperation and Development (OECD) 2015, PISA Result From PISA 2015, OECD Publishing, Paris.

Rusilowati A, Kurniawati L, Nugroho SE, \& Widiyatmoko A 2016, 'Developing an Instrument of Scientific Literacy Asessment on the Cycle Theme,' International Journal of Environtmental \& Science Education, vol. 11, pp. 5718-5727.

Sultan AA, Henson H, \& Fadde PJ 2018, 'Pre-Service Elementary Teachers' Scientific Literacy and Self-Efficacy in Teaching Science,' IAFOR Journal of Education, vol. 6, pp. 25-42.

Trefil J 2008, 'Science education for everyone: why and what?', Liberal Education, vol. 94, pp. 6-11. 